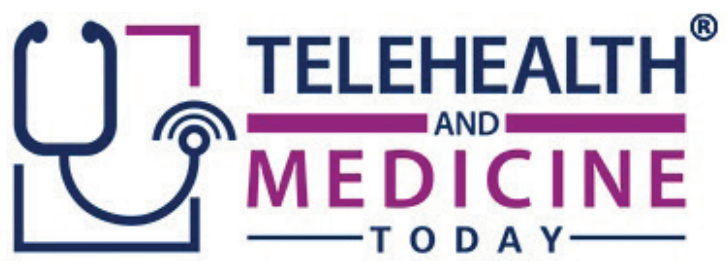

\title{
Avera eCARE: Medical Student Education in Telemedicine
}

Kelly Rhone ${ }^{1}$, Jennifer Lindgren ${ }^{2}$, Luke J. Mack ${ }^{3}$, Morgan E. Nelson ${ }^{4}$, Lindsay Spencer ${ }^{5}$, Susan M. Anderson ${ }^{6}$

Affiliations: ${ }^{1}$ Medical Director, Outreach and Innovation, Avera eCARE, Sioux Falls, South Dakota, and Assistant Professor, University of South Dakota, Sanford School of Medicine, Vermillion, South Dakota; ${ }^{2}$ Graduate Research Assistant, Avera eCARE, Sioux Falls, South Dakota; ${ }^{3}$ Manager, Research and Quality, Avera eCARE, Sioux Falls, South Dakota; ${ }^{4}$ Biostatistician, Avera Research Institute, Sioux Falls, South Dakota; University of South Dakota, Sanford School of Medicine, Sioux Falls, South Dakota; ${ }^{5}$ Coordinator, Research Program, Avera eCARE, Sioux Falls, South Dakota; ${ }^{6}$ Dean, Rural Medicine, University of South Dakota, Sanford School of Medicine, Sioux Falls, South Dakota

Corresponding author: Kelly Rhone, MD FACEP, Avera eCARE 4500 N Lewis Ave Sioux Falls, South Dakota, USA, 57104, Email: kelly.rhone@avera.org

Keywords: Avera, eCARE, Rural Communities, Telemedicine Education, Telemedicine Services, Urban Communities

Section: Original Research

The purpose of this research is to explore medical students' knowledge of and interest in telemedicine services in urban and rural communities. In the past, medical students reported feeling unprepared to use telemedicine and uninformed about laws regarding telemedicine usage following graduation. However, they also reported that telemedicine training is relevant and important for their future work.

Methods: Study participants included medical students taking part in a 2-day telemedicine education program in 2018 and 2019. The first day included a faculty seminar where students were introduced to telemedicine by experts in telemedicine innovations.
The second day was a simulation (SIM) day where medical students completed a rotation at the Avera eCARE virtual hospital hub. A survey was given prior to the faculty seminar and readministered following the SIM day. Questions were asked about telemedicine knowledge, curriculum, and willingness to practice via telemedicine.

Results: Chi-square analysis was used to look for associations pre/post by year. Both years showed an increase in favorable responses for questions to telemedicine training and education. For analyses by topic area, we created clusters of questions to build scores. T-tests were used to look for associations pre/post by year. The analysis 
resulted in three topic areas to build scores. Both years showed a significant increase in Rating of Overall Knowledge and Interest in Curriculum and Utilization. There was no significant difference in Willingness to Practice.

Conclusions: Results show notable differences in how students perceive and understand telemedicine after structured exposure to telemedicine services. Furthermore, this study demonstrates students' need for and interest in more telemedicine training opportunities in their curriculum. There was no significant difference in the willingness to practice in rural settings. Future studies may focus on how telemedicine training is perceived by those more willing to work in rural communities.

$\mathrm{T}$ The terms telehealth and telemedicine are often interchangeable, both referring to the use of remote healthcare technology to deliver clinical services. ${ }^{1}$ In 1996, the Institute of Medicine (IOM) released a report that defined telemedicine as "the use of electronic information and communications technologies to provide and support healthcare when distance separates the participants." 2

The application of telemedicine and telehealth has grown considerably since 1996. In 2012, the Health Resources and Services Administration (HRSA) sponsored the IOM to evaluate the evolution of telemedicine. ${ }^{3}$ Through this work, telemedicine is more commonly defined as "the use of medical information exchanged from one site to another via electronic communications to improve patients' health status." ${ }^{\prime, 3}$ The percentage of US hospitals fully or partially implementing computerized telehealth systems increased from $35 \%$ in 2010 to $76 \%$ in $2017 .{ }^{4}$
With a continued increase in telemedicine use by hospitals and physicians, it is vital for tomorrow's physicians to be properly trained on when and how to use telemedicine effectively. To do this, telemedicine competencies must be incorporated into medical education.

The push to add telemedicine competencies to medical training is supported and encouraged by the American Medical Association (AMA). In 2016, the AMA publicly adopted a policy aimed at ensuring medical students and residents are properly educated on the use of telemedicine in clinical practice. In addition, the AMA has awarded over 12.5 million USD (11.6 million EUR) in grants to medical schools to develop innovative curricula that can eventually be implemented across the country. ${ }^{5}$

Today's medical students are the first generation of "digital natives" - those who grew up surrounded by digital technology. ${ }^{6}$ While growing up with technology increases one's comfort and willingness to use new or existing technology, formal training is still necessary to provide high-quality medical care through telemedicine or other forms of healthcare technology. Integrating telemedicine into the medical school curriculum allows medical students to learn and personally experience similarities and differences, as well as advantages and limitations of telemedicine and traditional medicine. To provide proper video consultation via telemedicine, medical students must learn appropriate bedside and "webside" manner." Incorporating telemedicine into standardized medical training ensures that future physicians have the ability and confidence to use it in their practice.

Telemedicine exposure in medical training varies across the United States, ranging from required clinical rotations, to voluntary electives, to 
competitive fellowships. An annual survey conducted by the Association of American Medical Colleges revealed that the number of allopathic degree-granting medical schools in the United States, which included telemedicine in either a required or an elective course, increased from 57 (41\%) during the 2013-2014 academic year to $88(60 \%)$ during the 2017-2018 academic year. ${ }^{8}$

Falling into the current $60 \%$ are a handful of highly ranked medical schools. Harvard Medical School, Boston, offers a telemedicine elective for third- and fourth-year medical students and 3-6 months of telemedicine training for psychiatry and dermatology residents. George Washington University School of Medicine \& Health Sciences, Washington, DC, offers a 2-year telemedicine fellowship in emergency medicine. NYU School of Medicine and Weill Cornell Medical College, New York City, also offers telemedicine electives. The overarching goals of the telemedicine curriculum in these schools allow students to learn the history and progress of telehealth; observe and participate in the use of telehealth for patient care; and understand the advantages, limitations, and potential applications of telemedicine for the future of healthcare. ${ }^{7,9-12}$

In the past, medical students reported feeling unprepared to use telemedicine and uninformed about laws regarding telemedicine use following graduation. However, they also reported that telemedicine training is relevant and important for their future work. ${ }^{13}$ The purpose of this project is to explore medical student knowledge of and interest in telemedicine services in rural and urban communities before and after participating in a telemedicine education program.

\section{METHODS}

\section{Participants}

Almost all of the first-year medical students from the University of South Dakota Sanford School of Medicine, Vermillion, participated in this study, which was conducted in the spring of 2018 with the medical school class of 2021 and again in 2019 with the medical school classes of 2022.

There were 66 and 63 participants in 2018 and 2019 , respectively. Participants included firstyear medical students taking part in a 2-day telemedicine education program. Demographics of the 2021 and 2022 medical school classes are presented in Table 1. The class demographics provided by the University of South Dakota Sanford School of Medicine present class size for given year and gender. They classified rural areas in categories based on medical student's home communities with populations less than 10,000 and 30,000, respectively. ${ }^{14}$ We kept these categories to maintain consistency with the

Table 1. Class demographics provided by the University of South Dakota Sanford School of Medicine ${ }^{a, b}$

\begin{tabular}{|llc|} 
& \multicolumn{3}{c|}{ Class (\%) } & $\mathbf{2 0 2 2}$ \\
\hline Demographics & $\mathbf{2 0 2 1}$ & 66 \\
\hline Males & 64 & $40(60)$ \\
\hline Females & $38(59)$ & $26(40)$ \\
\hline Rural $<\mathbf{1 0 , 0 0 0}$ & $26(41)$ & $25(38)$ \\
\hline Rural $<\mathbf{3 0 , 0 0 0}$ & $27(42)$ & $39(60)$ \\
\hline
\end{tabular}

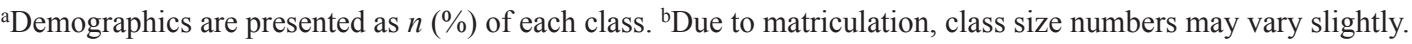


Table 2. Likert scale for survey questions

\begin{tabular}{|c|c|c|c|c|}
\hline \multicolumn{5}{|c|}{ Likert scale } \\
\hline 1 & 2 & 3 & 4 & 5 \\
\hline Poor & Fair & Average & Good & Excellent \\
\hline Well below average & Below average & Average & Above average & Well above average \\
\hline Not interested & Slightly interested & Somewhat interested & Interested & Very interested \\
\hline Not willing & Slightly willing & Neutral & Willing & Very willing \\
\hline
\end{tabular}

School of Medicine report. Participation in the study was voluntary, with no compensation.

\section{MATERIALS}

Survey questions created by Avera eCARE inquired about telemedicine knowledge, curriculum, and willingness to practice via telemedicine. Answers to survey questions consisted of four different 5-point Likert scales in addition to one seven-item response to assess population size that participants would prefer for their practice (Table 2).

The original survey was adjusted before the 2019 event to add four additional questions: two questions using a 5-point Likert scale and two open-response questions regarding personal reasons for wanting and not wanting to work with telemedicine in the future.

\section{Procedure}

Informed consent containing information about procedures, risks, benefits, duration, confidentiality, compensation, voluntary participation, and the purpose of the study was agreed to by the participants. In addition, contact information for the researchers was included in the consent form.

Participants received a paper-based survey prior to and immediately following the telemedicine education program in 2018 and 2019.

Participants were asked to answer each question as it relates to their own experiences and interests. After completing the presurvey, participants attended a didactic session on the past, current, and future utilization of telemedicine.

Day 2 of the program occurred 1 week after day 1 in 2019 and 4 months after day 1 in 2018 due to unavoidable weather. During the second day, participants returned to Avera eCARE for a tele-emergency simulation session.

First-year medical students took an active role in caring for a simulated patient by having a subject expert in a remote site to guide them through procedures, including intraosseous line placement, video laryngoscopy, intubation, needle thoracostomy, and chest tube placement via telemedicine technology. Participants engaged in informational sessions in various telemedicine specialties. These telemedicine specialties included, but not limited to, emergency medicine, intensive care, and senior care. Following the simulation, participants completed the postsurvey. Members of the research team were present when participants filled out the pre- and postsurvey.

\section{Analysis}

All analyses were conducted in SAS 9.4 software. Differences in responses were analyzed pre/post by year for each question asked and by topic area. Analyses were done separately by 
year because there were differences in response to some questions. For analyses of each question, the Likert scales were merged into binary responses. For questions with five responses (Q1-5, 7-10), responses $1-3$ and 4-5 were merged, respectively. For the question with seven responses (Q6), responses 1-4 and 5-7 were merged, respectively. Chi-square analysis was used to look for associations pre/post by year.

For analyses by topic area, PROC VARCLUS procedure within Statistical Analysis System 9.4 (SAS 9.4) was first used to find clusters of questions to build scores. Questions 1-5 and 7-8 were entered into this analysis. Q6 was excluded due to the difference in question type. Q9-10 were excluded as they were only asked in 2019. The analysis resulted in three topic areas to build scores. Q1-3 form the Rating of Overall Knowledge score, Q4-5 form Interest in Curriculum and Utilization score, and Q7-8 form Willingness to Practice score. The five-item questions for each score were added together to build each score. The max scores are 15, 10, and 10 respectively. $T$-tests were to look for associations pre/post by year.

\section{RESULTS}

Participants described themselves as $92 \%$ and $91 \%$ white in the 2021 and 2022 classes, respectively. Males made up 59\% of the 2021 class and $60 \%$ of the 2022 class. ${ }^{14}$

Analysis of pre- and postprogram responses for each question by year shows an increase in favorable responses for overall knowledge of telemedicine and overall knowledge of telemedicine compared with medical school peers for both 2018 and 2019 (Table 3).

In addition, analyses show a statistically significant increase in favorable responses for current medical training as it relates to telemedicine $(p<0.001, p<0.001)$ and interest in greater curriculum opportunities within the medical school program with a focus on telemedicine $(p=0.01, p=0.01)$ regarding 2018 and 2019, respectively. The year 2019 also shows an increase in favorable responses for interest in utilizing telemedicine in future practice. It is worth noting that while questions 6-10 do not have a statistically significant difference pre/post, all questions have a high frequency responding favorably to the preprogram survey, thus a large shift would be hard to detect. The results of this analysis are presented in Table 4.

Pre/post analysis of scores by year shows a statistically significant increase in the Rating of Overall Knowledge $(p<0.001, p<0.001)$ and Interest in Curriculum and Utilization $(p<$ $0.0028, p=0.0008$ ) for both 2018 and 2019, respectively. The Interest score increase is not to the same magnitude as the increase in Rating score, but the Interest score was relatively high in the preprogram surveys. There was no statistically significant difference in Willingness to Practice. The results of this analysis are presented in Table 5.

\section{DISCUSSION}

In this study, we utilize pre- and postsurveys to measure the impact of a 2-day telemedicine education program on the knowledge of and interest in telemedicine for first-year medical students. Results show increased knowledge and understanding of telemedicine following the education program. Participants also report increased interest in greater telemedicine opportunities within their medical education. These findings support previous claims that medical students view telemedicine training as both relevant and important for their future. ${ }^{13}$

Results regarding willingness to use telemedicine either from a rural setting by 
Table 3. Preanalysis and postanalysis for each survey question by year ${ }^{a}$

\begin{tabular}{|c|c|c|c|c|c|c|}
\hline \multirow{3}{*}{ Question } & \multicolumn{6}{|c|}{ Year } \\
\hline & \multicolumn{3}{|c|}{2018} & \multicolumn{3}{|c|}{2019} \\
\hline & $\begin{array}{c}\text { Pre } \\
(n=61)\end{array}$ & $\begin{array}{c}\text { Post } \\
(n=66)\end{array}$ & $p$ & $\begin{array}{c}\text { Pre } \\
(n=62)\end{array}$ & $\begin{array}{c}\text { Post } \\
(n=63)\end{array}$ & $p$ \\
\hline $\begin{array}{l}\text { 1. How would you rate your overall } \\
\text { knowledge of telemedicine? }\end{array}$ & 8 (13) & $57(86)$ & $<0.001$ & $4(6)$ & $61(97)$ & $<0.001$ \\
\hline $\begin{array}{l}\text { 2. How would you rate your overall } \\
\text { knowledge of telemedicine as compared } \\
\text { to your medical school peers? }\end{array}$ & $11(18)$ & $39(59)$ & $<0.001$ & $5(8)$ & $45(71)$ & $<0.001$ \\
\hline $\begin{array}{l}\text { 3. How would you rate your current medical } \\
\text { school training as it relates to current } \\
\text { advances and utilization of telemedicine? }\end{array}$ & $2(3)$ & $41(62)$ & $<0.001$ & $1(2)$ & $44(70)$ & $<0.001$ \\
\hline $\begin{array}{l}\text { 4. How interested would you be in greater } \\
\text { curriculum opportunities within your } \\
\text { medical school program focused on current } \\
\text { advances and utilization of telemedicine? }\end{array}$ & $32(52)$ & $49(74)$ & 0.01 & $37(60)$ & $51(81)$ & 0.01 \\
\hline $\begin{array}{l}\text { 5. How interested would you be in utilizing } \\
\text { telemedicine in future practice? }\end{array}$ & 47 (77) & $58(88)$ & 0.11 & $46(74)$ & $57(90)$ & 0.02 \\
\hline $\begin{array}{l}\text { 6. Based on population, in what size } \\
\text { community would you most like to practice? }\end{array}$ & $29(50)$ & $33(51)$ & 0.93 & $34(56)$ & $40(66)$ & 0.27 \\
\hline $\begin{array}{l}\text { 7. How would you rate your willingness to } \\
\text { practice in a rural setting? }\end{array}$ & $31(52)$ & $23(35)$ & 0.07 & $23(37)$ & $25(40)$ & 0.77 \\
\hline $\begin{array}{l}\text { 8. How would you rate your willingness to } \\
\text { practice in a rural setting if telemedicine } \\
\text { were available to assist with patient care, } \\
\text { consultation, etc.? }\end{array}$ & $39(65)$ & $41(63)$ & 0.82 & $27(44)$ & $30(48)$ & 0.65 \\
\hline $\begin{array}{l}\text { 9. How would you rate your willingness to } \\
\text { work as a telemedicine provider, offering } \\
\text { patient care and/or consultation to a distant } \\
\text { location? }\end{array}$ & - & - & - & $36(58)$ & $45(71)$ & 0.12 \\
\hline $\begin{array}{l}\text { 10. How would you rate your willingness of } \\
\text { pursuing a specialty that currently utilizes } \\
\text { telemedicine? }\end{array}$ & - & - & - & $40(65)$ & $48(76)$ & 0.15 \\
\hline $\begin{array}{l}\text { 11. What is the primary reason you would } \\
\text { want to work with telemedicine in the } \\
\text { future? }\end{array}$ & - & - & - & - & - & - \\
\hline $\begin{array}{l}\text { 12. What is your greatest hesitation in } \\
\text { working with telemedicine in the future? }\end{array}$ & - & - & - & - & - & - \\
\hline
\end{tabular}

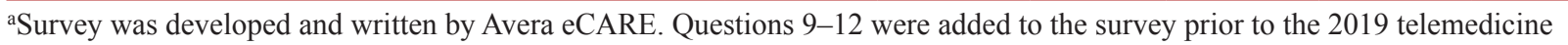
education program. Results of the Chi-square analysis per year are presented as $n(\%)$ of each pre/post group that responded with 4-5 for Q1-5, 7-10 and responded with 5-7 for Q6. 
Table 4. Pre/post analysis of scores by year

\begin{tabular}{|c|c|c|c|c|c|c|}
\hline \multirow[t]{2}{*}{ Score } & \multicolumn{3}{|c|}{2018} & \multicolumn{3}{|c|}{2019} \\
\hline & $\begin{array}{c}\text { Pre } \\
(n=61)\end{array}$ & $\begin{array}{c}\text { Post } \\
(n=66)\end{array}$ & $P$ & $\begin{array}{c}\text { Pre } \\
(n=62)\end{array}$ & $\begin{array}{c}\text { Post } \\
(n=63)\end{array}$ & $P$ \\
\hline $\begin{array}{l}\text { Rating of overall knowledge } \\
(\mathrm{Q} 1-3) \text { Max Score }=15\end{array}$ & $7.4( \pm 2.11)$ & $11.3( \pm 1.81)$ & $<0.001$ & $6.5( \pm 2.12)$ & $12.0( \pm 1.47)$ & $<0.001$ \\
\hline $\begin{array}{l}\text { Interest in curriculum and } \\
\text { utilization }(\mathrm{Q} 4-5) \\
\text { Max Score }=10\end{array}$ & $7.7( \pm 1.45)$ & $8.5( \pm 1.53)$ & 0.003 & $7.5( \pm 1.79)$ & $8.5( \pm 1.49)$ & $<0.001$ \\
\hline $\begin{array}{l}\text { Willingness to practice }(\mathrm{Q} 7-8) \\
\text { Max Score }=10\end{array}$ & $7.0( \pm 1.93)$ & $6.7( \pm 1.92)$ & 0.45 & $6.3( \pm 2.15)$ & $6.6( \pm 2.08)$ & 0.41 \\
\hline
\end{tabular}

Results of the $T$-tests of each score are presented as mean $( \pm \mathrm{SD})$ of each pre/post group.

Table 5. Pre/post analysis of scores by year

Scores

Pre

$(n=61)$

Rating of overall knowledge $7.4( \pm 2.11) \quad 11.3( \pm 1.8$

(Q1-3) Max Score = 15

Interest in curriculum and

utilization (Q4-5)

Max Score $=10$

Willingness to practice

(Q7-8) Max Score $=10$

2018 Post

$7.7( \pm 1.45) \quad 8.5( \pm 1.53) \quad 0.003 \quad 7.5( \pm 1.79) \quad 8.5( \pm 1.49) \quad<0.001$
$p$-value Pre $(n=62)$ 2019 Post $p$-value $(n=63)$

$6.5( \pm 2.12)$

$6.5( \pm 2.12) \quad 12.0( \pm 1.47)<0.001$ $7.5( \pm 1.79) \quad 8.5( \pm 1.49) \quad<0.001$

$7.0( \pm 1.93) \quad 6.7( \pm 1.92) \quad 0.45$

$6.3( \pm 2.15) \quad 6.6( \pm 2.08)$

0.41 requesting assistance from a telemedicine hub or providing telemedicine services as a physician at a hub site to a distant site do not show statistically significant differences, but both questions have a high frequency of favorable responses in the presurvey.

Future research on willingness to use telemedicine as a rural provider or practice telemedicine within a hub may be of value as the medical student advances and becomes more specialized within the medical school program. A nationwide increase in use and willingness to use telemedicine in both current and future physicians indicates the importance of incorporating telemedicine into the medical school curriculum and training. ${ }^{15}$

Participants of this study report increased access to care, more efficient use of time, and improved patient outcomes as primary reasons to work with telemedicine in the future. These results agree with comparable literature on reasons for willingness to utilize telemedicine for practicing physicians. ${ }^{15}$

Participants also report the importance of being educated on telemedicine and their willingness to learn given that it will better prepare them to practice medicine, indicating a desire from 
current medical students for integration of telemedicine into their medical training.

There was no statistically significant difference in willingness to practice in rural settings.

Future studies may focus on how telemedicine training is perceived by those more willing to work in rural communities. Authors of similar studies encourage further investigation to find the most effective methods for the implementation of a telemedicine curriculum into medical education. ${ }^{13}$ Future studies may also focus on determining the proportion of medical students in this study who pursue a medical career in rural settings or specialties utilizing telemedicine. Lastly, it may be of interest to repeat this study in another rural or potentially urban medical school for comparability.

Conclusions: Results show notable differences in how students perceive and understand telemedicine after structured exposure to telemedicine services. Furthermore, this study demonstrates students' need for and interest in more telemedicine training opportunities in their curriculum. There was no significant difference in the willingness to practice in rural settings. Future studies may focus on how telemedicine training is perceived by those more willing to work in rural communities.

Acknowledgments: The authors wish to thank the University of South Dakota Sanford School of Medicine for participation in this study.

Conflicts of Interests: The authors report no conflicts of interest.

Contributors: K.R., S.A., L.S., and L.M. made substantial contributions to the conception or design of the work; K.R., S.A., J.L., L.S., and
L.M. contributed to the acquisition, K.R., L.M., and M.N. contributed to the analysis and K.R., S.A., M.N., J.L., L.S., and L.M. contributed to the interpretation of data for the work. K.R., S.A., J.L., L.S., M.N., and L.M. contributed to drafting the work or revising it critically for important intellectual content. K.R., S.A., J.L., L.S., M.N., and L.M. contributed to the final approval of the version to be published. K.R., S.A., J.L., L.S., M.N., and L.M. are in agreement to be accountable for all aspects of the work in ensuring that questions related to the accuracy or integrity of any part of the work are appropriately investigated and resolved.

\section{Funding statement: None}

Ethical Approval: This study was approved by the Institutional Review Board of the University of South Dakota as exempt (protocol no. 2018.055).

\section{REFERENCES}

1. Committee on Pediatric W, Marcin JP, Rimsza ME, Moskowitz WB. The use of telemedicine to address access and physician workforce shortages. Pediatrics. 2015;136(1):202-9. https://doi.org/10.1542/ peds.2015-1253

2. In: Field MJ, editor. Telemedicine: A guide to assessing telecommunications in health care. The National Academies Collection: Reports funded by National Institutes of Health. Washington, DC; 1996.

3. The role of telehealth in an evolving health care environment: Workshop summary. Washington, DC; 2012.

4. Association AH.Fact sheet: Telehealth. AHA; 2019. Available from: https://www.aha.org/ factsheet/telehealth

5. Association AM. AMA encourages telemedicine training for medical students, residents. 2016 [cited 2020 Aug 04]. Available from: https://www. ama-assn.org/press-center/press-releases/ 
ama-encourages-telemedicine-trainingmedical-students-residents

6. Pathipati AS, Azad TD, Jethwani K. Telemedical education: Training digital natives in telemedicine. J Med Internet Res. 2016;18(7):e193. https://doi.org/10.2196/ jmir.5534

7. Warshaw R. From bedside to webside: Future doctors learn how to practice remotely. 2018 [cited 2020 Aug 04]. Available from: https:// news.aamc.org/medical-education/article/ future-doctors-learn-practice-remotely/

8. AAMC. Content documentation in required courses and elective courses. 2019 [cited 2020 Aug 04]. Available from: https://www. aamc.org/initiatives/cir/406462/06a.html

9. Cohen J. How 4 hospitals, universities are teaching med students "Website Manner": Becker's Hospital review. 2018 [cited 2020 Aug 04]. Available from: https://www. beckershospitalreview.com/telehealth/how4-hospitals-universities-are-teaching-medstudents-website-manner.html

10. Khullar D. Telemedicine is getting trendy, but doctors may not be keeping up: The Washington Post. 2018 [cited 2020 Aug 04]. Available from: https://www.washingtonpost. $\mathrm{com} /$ national/health-science/telemedicineis-getting-trendy-but-doctors-may-not-bekeeping-up/2018/04/20/681e1644-2178-11e8badd-7c9f29a55815_story.html?noredirect $=$ on

11. Sikka N. Telemedicine: Overview of fellowship. 2019 [cited 2020 Aug 04]. Available from: https://smhs.gwu.edu/emed/ education-training/fellowships/telemedicine
12. Health NL. Telehealth-technology transforming healthcare delivery elective. 2019 [cited 2020 Aug 04]. Available from: https://med.nyu.edu/education/md-degree/ registration-student-records/electivecatalog/department-medicine/telehealthelective

13. Waseh S, Dicker AP. Telemedicine training in undergraduate medical education: Mixed-methods review. JMIR Med Educ. 2019;5(1):e12515. https://doi. org/10.2196/12515

14. Bragg D. Dean, Student Affairs, University of South Dakota Sanford School of Medicine. Personal communication with S. Anderson, October 2019.

15. Well A. Telehealth index: 2019 consumer survey. 2019 [cited 2020 Aug 04]. Available from: https:/www.americanwell.com/ resources/telehealth-index-2019-consumersurvey/

Copyright Ownership: This is an open access article distributed in accordance with the Creative Commons Attribution Non Commercial (CC BY-NC 4.0) license, which permits others to distribute, adapt, enhance this work non-commercially, and license their derivative works on different terms, provided the original work is properly cited and the use is noncommercial. See: http://creativecommons. org/licenses/by-nc/4.0. 